\title{
Professionalism in Medical Practice
}

\section{Kutubi A}

\section{Introduction:}

The word "profession" and "professional" come from the Latin word "professio" which means a public declaration with the force of a promise. Professions are a group which declare in a public way that their members promise to act in certain ways and that the group and the society may discipline those who fail to do so.The profession presents itself to society as a social benefit and society accepts the profession, expecting it to serve some important social goal.The profession usually issues a code of ethics stating the standards by which its members can be judged.

\section{What is Professionalism:}

Medical professionalism forms the basis of the contract between doctors and the society. American Board of Internal Medicine defined professionalism as having six components : altruism, accountability, excellence, duty, honour, integrity and respect for others. These values should provide guidance for promoting professional behavior and for making difficult ethical decisions. Medical professionalism in the New Mllennium was issued jointly by the American Board of Internal Medicine, the American College of Physicians and the European Federation of Internal Medicine in 2002. Subsequently,90 professional associations including most of the speciality and subspeciality groups in American Medicine have endorsed the Physician Charter.

The fundamental principles of professionalism are stated as

1. The primacy of patient welfare

2. Patient autonomy

3. Social justice.

Professional responsibilities that follow from these principles are commitment to competency, to honesty with patients, to confidentiality, to appropriate relationship with patients, to improving quality of care, to improving access to care, to a just distribution of finite resource, to scientific knowledge, to maintaining trust by managing conflicts of interest and to professional responsibilities.
[J Shaheed Suhrawardy Med Coll 2016; 8(2): 37-38] DOI: http://dx.doi.org/10.3329/jssmc.v8i2.37240

\section{Professionalism and physicians judgments :}

One of the principal attributes of professionalism is independent judgment about technical matters relevant to the expertise of the profession. The purpose of this independent judgment is to assure that general technical knowledge is appropriately applied to particular cases. Today, many physicians work in managed care situations that require them to abide by policies and rules regarding forms of treatment, time spent with patients, use of pharmaceuticals, etc. It should be designed to enhance and improve professional judgment,not limit it. For example requiring consultation is ethically obligatory in doubtful clinical situations,penalizing consultation for financial reasons would be ethically wrong.Also requiring physicians to adhere to practice guidelines and to consult outcome studies may improve professional judgment, requiring blind adherence to those guidelines may be a barrier to the exercise of professional judgment. The presence of rules, policies and guidelines in managed care settings requires the physicians who work in these settings to make such judgments and to express their reasoned criticism of any that force the physicians to violate the principles of professionalism.

\section{Professionalism in action :}

- Patients need good doctors. Good doctors make the care of their patients their first concern : they are competent, keep their knowledge and skills upto date, establish and maintain good relationships with their patiente and colleagues,are honest and trustworthy, and act with integrity and within the law.

- $\quad$ Good doctors work in partnership with patients and respect their rights to privacy and dignity. They treat each patients as an individual. They do their best to make sure all patients receive good care and treatment that will support to live as well as possible,whatever their illness or disability.

- Good medical practice describes what is expected of all doctors registered with the General Medical Council. It is their responsibility to be familiar with good medical practice and the explanatory guidance 
which supports it, and to follow the guidance they contain.

- Doctors must use their judgment in applying the principles to the various situations they will face as a doctor,whether or not they hold a licence to practice, whatever field of medicine they work in and whether or not they routinely see patients. They must be prepared to explain and justify their decisions and actions.

\section{Teaching Professionalism in Medical Education :}

Ironically while medical educators love discussing professionalism this word has become despised by medical students. Any efforts to teach professionalism to students seem preachy and insincere. So what's a medical educators to do? Professional behavior should be developed at an early stage of a doctors training and likely to be continued throughout their career.How professional behavior can be taught? It must be included in formal and informal (hidden) curriculum. Despite considerable advances in the incorporation of professionalism into the formal curriculum,medical students and residents are too often presented with a mechanical, unreflective version of the topic that fails to convey deeper ethical and humanistic aspiration. Some misunderstandings of professionalism are exacerbated by the commonly used assessment tools that focus only on superficial observable behavior and not on moral values and attitudes. The key precepts needed for a robust presentation of professionalism can be grouped under two headings,'Proessionalism as a trust generating promise', representing commitments to patients interest, more than a mere business, a social contract, a public and collective promise and hard work and 'professionalism as application of virtue to practice', based on virtue, deeper attitudes rather than mere behavior and requiring of practical wisdom. These key precepts help students to avoid many common unreflecting misunderstandings of professionalism and guide faculty stuffs and students jointly to address the deeper issues required for successful professional identity formation.

\section{Conclusion:}

Professionalism represents a commitment to placing the interests of the patient ahead of those of the professional. The term Professionalism is derived from the verb 'To profess 'which means 'To promise'. The health professional have to promise the community at large to place the interests of the patient foremost. 